\title{
Registrar perceptions on general surgical training in South Africa: A report by the South African Society of
Surgeons in Training (SASSiT)
}

\author{
N Patel, ${ }^{1}$ A Leusink, ${ }^{2}$ N Singh, ${ }^{3}$ MZ Koto, ${ }^{3}$ T Luvhengo ${ }^{4}$ \\ ${ }^{1}$ Department of Paediatric Surgery, University of Witwatersrand, Johannesburg, South Africa \\ ${ }^{2}$ Department of Surgery, Chris Hani Baragwanath Academic Hospital, Johannesburg, South Africa \\ ${ }^{3}$ Department of Surgery, Sefako Magkatho University, Pretoria, South Africa \\ ${ }^{4}$ Department of Surgery, University of the Witwatersrand, Johannesburg, South Africa
}

Corresponding author: N Patel (niravpatel44@gmail.com)

\begin{abstract}
Background: Surgical training varies significantly amongst universities within the same country. This trend is reflected in South Africa and provides an opportunity for innovation to improve the quality of general surgical training.

Objective: To assess the perceptions of South African general surgery registrars regarding surgical training.

Method: A prospective descriptive study was performed by means of a confidential questionnaire distributed to general surgical registrars at all eight training centers in South Africa. Participants were asked to give comments regarding adequacy of formal academic teaching, level of supervision during surgical procedures, exposure to and training in minimally invasive surgery (MIS), and preparation for examinations. Descriptive statistics were generated with Microsoft Excel. Ethics clearance was obtained from the University of the Witwatersrand Human Research Ethics Committee.

Results: Of 200 questionnaires distributed 105 (52.5\%) were returned. 44\% (105/241) of all registrars from six training institutions participated. $89.5 \%(94 / 105)$ of respondents reported that they attended less than six hours of formal academic teaching per week and 71.4\% (75/105) indicated that their institution offered less than six hours of formal academic teaching per week. $76.2 \%(80 / 105)$ of respondents regarded lack of protected academic time as the greatest obstacle to their surgical training and $95.2 \%(99 / 105)$ reported that clinical responsibilities prevented them from attending formal academic teaching regularly. Overall, only 31.4\% (33/105), 41.9\% (44/105) and 37.1\% (39/105) were satisfied with the amount of formal academic teaching, level of supervision during theatre procedures and exposure to minimally invasive surgery respectively. Lack of resources and lack of appropriate skills were identified as a hindrance to MIS training by $47.6 \%(50 / 105)$ and $28.6 \%$ (30/105) of respondents respectively.

Conclusion: Surgical registrars are dissatisfied with the amount of formal academic teaching and protected academic time, level of supervision in theatre and their exposure to MIS. These challenges compromise trainees' ability to practice independently after qualification. Numerous interventions are necessary and possible to address these challenges.

Key words: Surgery, Training, Education, South Africa
\end{abstract}

S Afr J Surg 2018;56(2)

http://dx.doi.org/10.17159/2078-5151/2018/v56n2a2448

\section{Introduction}

Surgical training has undergone major changes in the past decade, both internationally and in South Africa. ${ }^{1}$ These changes are the result of various factors which include trainee work hour restrictions (intended to mitigate trainee fatigue and improve patient safety), ${ }^{1}$ the proliferation of minimally invasive surgery, ${ }^{2}$ development of surgical subspecialties, involvement of other specialties in the definitive care of surgical patients, changes in population disease profiles and funding priorities directing surgical pathology away from academic training centers. ${ }^{3}$ In South Africa, the now mandatory completion of a research component of specialist training is another factor contributing to change. This issue was the first sphere of registrar training examined by SASSiT, with results disseminated by Patel et al. in their article 'South African general surgical registrars perceptions of the research component of training: Hope for the Future $?^{4}$ In the United States the changing landscape of surgical training prompted the 2004 American Surgical Association Blue Ribbon Committee Report on Surgical Education. This report 
emphasised the need for surgical training to be tailored to the needs of specific disease profiles and to incorporate new technologies in order to compensate for the decreased patient exposure encountered in the training of the modern surgeon. ${ }^{5}$ Surgical training varies significantly amongst universities within the same country. This trend is reflected in South Africa and provides an opportunity for innovation to improve the quality of general surgical training.

A survey of general surgical residents in the United States revealed that nearly $40 \%$ of new graduates lack confidence in their surgical skills., ${ }^{5,6}$ The same survey found that up to $80 \%$ of the surgical graduates elect to undertake post graduate fellowships in order to gain the confidence, maturity and clinical acumen required for independent practice. ${ }^{5,6}$ In South Africa, a 2014 study found that newly qualified specialists felt that there was insufficient exposure to the latest surgical techniques during their training, particularly in the field of minimal invasive surgery (MIS). ${ }^{7}$ Furthermore, a 2014 study by Kruger et al. demonstrated that $61 \%$ of all procedures performed by surgical trainees in South Africa during the course of their training were unsupervised. ${ }^{8}$ The immediate enrolment of newly qualified trainees into fellowship programs is detrimental in low and middle income countries with significant shortages of general surgeons, high patient volumes and a wide variety of surgical pathology. Given the paucity of literature on surgical training in the local setting and within the current context of local and international challenges to surgical training, there is an urgent need to review current surgical curricula and training methods. This study aimed to assess the perceptions of general surgery registrars in South Africa regarding the adequacy of their surgical training.

\section{Methods}

A prospective descriptive study was performed by means of a confidential questionnaire. The registrar representative of the South African Society of Surgeons in Training (SASSiT) at each university distributed questionnaires to surgical registrars in each department. The questionnaire was divided into four sections that assessed perceptions on: (i) time dedicated to formal academic teaching, (ii) supervised surgical training within theatre, (iii) exposure to and training in MIS, and (iv) major hindrances to surgical training. Descriptive statistics were generated with Microsoft Ethics. Clearance was obtained from the University of Witwatersrand Human Research Ethics Committee. A total of 200 questionnaires were distributed to surgical registrars at 8 universities in South Africa. All participants provided written consent; participation was voluntary and no participant received material benefit from participation. No identifying data were captured.

\section{Results}

Of 200 questionnaires distributed, 52.5\% (105/200) were returned representing $43.5 \% \quad(105 / 241)$ of all surgical registrars nationally. Respondents spanned six of the eight medical universities in South Africa. For breakdown of respondents according to institution and year of study see Table 1 and Table 2. Specific universities are not identified in order to minimise potential for identification of respondents.

\begin{tabular}{lll}
\multicolumn{3}{l}{ Table 1: Respondents disaggregated by University } \\
\hline Institution & Number (N=105) & Percentage \\
\hline University A & 29 & $27.6 \%$ \\
University B & 27 & $25.7 \%$ \\
University C & 17 & $16.2 \%$ \\
University D & 11 & $10.5 \%$ \\
University E & 11 & $10.5 \%$ \\
University F & 10 & $9.5 \%$
\end{tabular}

Table 2: Respondents disaggregated by year of study

\begin{tabular}{lll}
\hline Institution & Number $(\mathbf{N}=\mathbf{1 0 5})$ & Percentage \\
\hline Year 1 & 23 & $21.9 \%$ \\
Year 2 & 14 & $13.3 \%$ \\
Year 3 & 29 & $27.6 \%$ \\
Year 4 & 24 & $22.8 \%$ \\
Year 5 & 13 & $12.4 \%$ \\
Year 6 & 2 & $2.0 \%$
\end{tabular}

As presented in Table 3, 71.4\% (75/105) of respondents reported that their institution offered less than six hours of formal academic teaching per week and 89.5\% (94/105) indicated that they attended less than six hours of academic teaching weekly. $95.2 \%(99 / 105)$ reported that clinical responsibilities prevented them from attending formal academic teaching regularly and $31.4 \%$ (33/105) were satisfied with the amount of formal academic teaching offered at their institution.

Table 3: Breakdown of registrars according to number agreeing with statements regarding formal academic teaching $(\mathrm{N}=105)$

\begin{tabular}{|c|c|c|}
\hline Parameter & Number & Percentage \\
\hline $\begin{array}{l}\text { Less than } 6 \text { hours formal teaching } \\
\text { offered at institution per week. }\end{array}$ & 75 & $71.4 \%$ \\
\hline $\begin{array}{l}\text { Less than } 6 \text { hours of formal teaching } \\
\text { attended by registrars per week. }\end{array}$ & 94 & $89.5 \%$ \\
\hline $\begin{array}{l}\text { Responsibilities of surgical unit } \\
\text { being the major obstacle preventing } \\
\text { attendance of formal teaching. }\end{array}$ & 99 & $95.2 \%$ \\
\hline $\begin{array}{l}\text { Academic teaching at institution is } \\
\text { useful in preparation for FCS (SA) } \\
\text { Examination. }\end{array}$ & 59 & $56.2 \%$ \\
\hline $\begin{array}{l}\text { Academic teaching at institution is } \\
\text { useful in preparation for independent } \\
\text { practice. }\end{array}$ & 62 & $59.0 \%$ \\
\hline $\begin{array}{l}\text { Do you feel satisfied with the } \\
\text { amount of formal teaching offered at } \\
\text { your institution? }\end{array}$ & 33 & $31.4 \%$ \\
\hline \multicolumn{3}{|c|}{$\begin{array}{l}\text { FCS }(\mathrm{SA})=\text { Fellow of the College of Surgeons in the Colleges o } \\
\text { Medicine of South Africa }\end{array}$} \\
\hline
\end{tabular}


$85.7 \%(90 / 105)$ of respondents reported receiving less than six hours of supervised surgical training per week and only $20.9 \%(22 / 105)$ reported the opportunity to be the primary surgeon in more than half of all elective cases. Only $37.1 \%$ (39/105) of registrars reported receiving adequate training in MIS. Further data on registrar perceptions of supervised surgical training are presented in Table 4.

\begin{tabular}{|c|c|c|}
\hline Parameter & Number & Percentage \\
\hline $\begin{array}{l}\text { Registrars receive less than } 6 \text { hours of } \\
\text { supervised surgical training per week. }\end{array}$ & 90 & $85.7 \%$ \\
\hline $\begin{array}{l}\text { Registrars are given the opportunity to } \\
\text { be primary surgeon in more than } 50 \% \text { of } \\
\text { elective cases. }\end{array}$ & 22 & $20.9 \%$ \\
\hline $\begin{array}{l}\text { Supervised surgical training at institution } \\
\text { is useful in preparation for FCS (SA) } \\
\text { Examination. }\end{array}$ & 59 & $56.2 \%$ \\
\hline $\begin{array}{l}\text { Supervised surgical training at institution } \\
\text { is useful in preparation for independent } \\
\text { practice. }\end{array}$ & 62 & $59.0 \%$ \\
\hline $\begin{array}{l}\text { Do you feel satisfied with the amount of } \\
\text { supervised surgical training offered at } \\
\text { your institution? }\end{array}$ & 44 & $41.9 \%$ \\
\hline $\begin{array}{l}\text { Registrars receive adequate training in } \\
\text { minimally invasive surgery. }\end{array}$ & 39 & $37.1 \%$ \\
\hline
\end{tabular}

Lack of resources and appropriate skills were identified as hindrances to MIS training by $47.6 \%$ (50/105) and $28.6 \%$ (30/105) of respondents, respectively. 76.2\% (80/105) of respondents regarded lack of protected academic time as the greatest hindrance to their surgical training. These data are presented in Table 5 .

Table 5: Distribution of registrars according to number who agreed with factors identified as hindrances to surgical training $(\mathrm{N}=105)$

\begin{tabular}{lcc}
\hline Parameter & Number & Percentage \\
\hline $\begin{array}{l}\text { The greatest hindrance to training in } \\
\text { minimally invasive surgery at institution }\end{array}$ & 50 & $47.6 \%$ \\
is lack of resources. & & \\
$\begin{array}{l}\text { The greatest hindrance to training in } \\
\text { minimally invasive surgery at institution }\end{array}$ & 30 & $28.6 \%$ \\
is lack of skills. & \\
$\begin{array}{l}\text { The greatest hindrance on overall training } \\
\text { is insufficient protected time. }\end{array}$ & 80 & $76.2 \%$ \\
$\begin{array}{l}\text { The greatest hindrance on overall } \\
\text { surgical training is insufficient consultant } \\
\text { involvement. }\end{array}$ & 18 & $17.1 \%$ \\
\end{tabular}

\section{Discussion}

General surgical training in South Africa is sought after by international and local trainees due to an abundance of surgical pathologies and the opportunity for hands-on experience. ${ }^{9}$ Training in general surgery is offered at eight medical schools in South Africa. Although examinations and registration are centralised, the responsibility for training falls on the surgical department of each of the medical schools. Training methodologies vary significantly between departments leading to disparities in the academic and clinical exposure of trainees. ${ }^{10}$ Disparity in training is due to numerous factors including the existence of specialised surgical units, access to specialised surgical equipment, the use of extended training programs (such as regional hospitals) and the ability for some centres to offer training opportunities in private university affiliated institutions. ${ }^{11}$ For the majority of surgical registrars clinical training occurs exclusively within public sector hospitals experiencing challenges such as staff and other resource shortages, poor infrastructure, and high patient loads. ${ }^{12}$

It is concerning that less than one third of registrars (31.4\%) are satisfied with the amount of formal academic teaching offered at their institution and that close to $90 \%$ attend less than six hours of academic teaching per week. This is despite the fact that the majority of registrars (59\%) agree that formal teaching is vital in the preparation of surgical trainees for independent practice. An overwhelming majority (95.2\%) of registrars consider clinical responsibilities the main obstacle to participation in academic teaching. Further, $76.2 \%$ of registrars identified a lack of protected academic time as a key impediment to surgical training. Emphasis on service delivery over academic commitments is a recurring finding in local studies over the past two decades as reflected in Thomson and Baker ${ }^{13}$ and Kong et al. ${ }^{1}$ Due to the large burden of disease and shortage of general surgeons in the public service in South Africa, general surgical trainees are required to compromise on academic activities in the interest of patient care. Addressing the balance between service delivery, protected academic time and trainee fatigue is a challenge for the South African academic surgical community that remains to be adequately addressed.

Nearly $86 \%$ of trainees reported receiving less than six hours of supervised surgical training with a consultant per week. Furthermore, less than half of the respondents $(41.9 \%)$ are satisfied with the amount of supervision when it is provided. This finding of the low level of supervision of surgical trainees is consistent with the findings of Kruger and Veller ${ }^{8}$ who found that $61 \%$ of surgical procedures performed by South African general surgical trainees were unsupervised. In Nigeria, a recent study reported that less than $50 \%$ of surgical trainees were satisfied with their experience of supervised surgical training. ${ }^{14}$ A recent comparison of the surgical exposure of trainees in the United Kingdom (UK) and South Africa revealed that trainees in the UK experienced nearly double the amount of consultant supervision in theatre as those in SA. ${ }^{15}$ The low level of supervision reported in 
this study may be due to the shortage of general surgical consultants in the public sector, and the pull of private practice for those working in both public and private sectors. Surgical training in South Africa remains Halsteadian in nature. ${ }^{7}$ In this environment, the transformation of a trainee into a competent surgeon is strongly influenced by senior supervision. . $^{5,14,16}$

Minimal access surgery is now considered best practice in the management of a range of surgical pathologies. As demonstrated in certain centers in South Africa, the adoption and growth of MIS is possible within the public health sector. ${ }^{17}$ MIS is well established and even flourishing within certain public training centres. This demonstrates that so called 'technologically advanced' surgery need not be the domain of the private sector in South Africa. This said, less than half of surgical trainees $(37.1 \%)$ are currently satisfied with their training in MIS. Adequate training in MIS necessitates exposure to techniques of laparoscopy and ongoing exposure and supervised practice. ${ }^{17}$ This may be facilitated through surgical skills laboratories, surgical simulators, ${ }^{17}$ web based expert tutorials, ${ }^{18}$ and laparoscopy courses. Lack of resources $(47.6 \%)$ and lack of necessary skills $(28.6 \%)$ were identified as the greatest obstacles to training in MIS. These findings are similar to those of De Beer et al. ${ }^{7}$ and Apostolou et al. ${ }^{17}$ who also identified lack of resources as the main impediment to laparoscopy in the South African public health sector. Further, they concluded that training in laparoscopy in South Africa was sub-optimal ${ }^{17}$ and required a concerted effort from the surgical fraternity and public health administrators to address.

\section{Limitations}

We acknowledge that this study was limited by the low sample size, the fact that results were not reported by institution (to minimise the potential for real or imagined repercussions for respondents) and that only 6 of 8 training centers in the country were sampled. This said, we believe this study highlights important trends inhibiting surgical training in South Africa.

\section{Conclusion}

General surgical registrars are concerned with the current training programme which they perceive to be confronted by three main challenges. These are lack of protected academic time, inadequate senior supervision in theatre and insufficient exposure to MIS. There is doubt amongst registrars that the level of training currently received is adequate to impart sufficient skills and acumen to practice independently upon qualification. South Africa has a long tradition of training skilled surgeons. ${ }^{10}$ The challenges presented above necessitate a review of surgical training in order to maintain this proud tradition.

\section{Recommendations}

On the basis of our findings and given that the immediate enrolment of newly qualified specialists in fellowship programmes in low and middle income countries (such as South Africa) with small specialist pools and high surgical needs may be detrimental to the surgical needs of these countries, we suggest that the current model for general surgical training be reviewed. We propose greater monitoring of the academic and service delivery responsibilities of consultants employed in the public and private sectors. We also suggest mentorship programmes for junior specialists, as utilised by the American College of Surgeons, ${ }^{18}$ with the objective of reinvigorating the role of general surgery consultants within the public sector. Additionally, we propose the mandatory completion of courses in MIS as a prerequisite for qualification and the creation of opportunity for registrars to rotate through well-established local MIS centers. Discrepant access to the private sector through university affiliated academic surgical departments may be addressed by offering those universities without access to private academic centres the opportunity to formally rotate their trainees through those that do. Finally, we propose the institution and enforcement of minimum provision and attendance requirements on academic activities for general surgery trainees.

\section{Acknowledgements}

The authors would like to thank Dr. Tumi Mabogoane, Dr. Siddharth R Gautam, Dr. Chun-Yen Wu and Dr Megan Peffer for their contribution.

\section{REFERENCES}

1. Kong VY, Odendaal JJ, Clarke DL. Surgical resident working hours in South Africa. S Afr J Surg. 2015;53(3):8-10. Available from: http://dx.doi.org/10.7196/SAJS.7845

2. Mattar SG, Alseidi AA, Jones DB, et al. General Surgery Residency Inadequately Prepares Trainees for Fellowship. Ann Surg. 2013;258(3):440-9. Available from: http://dx.doi. org/10.1097/SLA.0b013e3182a191ca

3. Krige JEJ. Departments of Surgery in South Africa - legacies of the past, challenges for the future. S Afr J Surg. 2004;42(3):767.

4. Patel N, Naidoo P, Govender T, et al. South African general surgery registrar perceptions of the research component of training: Hope for the future? S Afr Med J. 2016;106(2):16971. Available from: http://dx.di.org//10.7196/SAMJ.2016. v106i2.10310

5. Debas HT, Bass B, Brennan MF, et al. American Surgical Association Blue Ribbon Committee Report on Surgical Education: 2004. Ann Surg. 2005;241(1):1-8. Available from: http://dx.doi.org/10.1097/01.sla.0000150066.83563.52

6. Sachdeva AK, Bell RH, Britt LD, et al. National Efforts to Reform Residency Education in General Surgery. Acad Med. 2007;82(12):1200-10. Available from: http://dx.doi. org/10.1097/ACM.0b013e318159e052

7. De Beer MM, Karusseit VOL, Pienaar BH. Perspectives of South African general surgeons regarding their postgraduate training. S Afr J Surg. 2014;52(3):67-71. Available from: http:// dx.doi.org/10.7196/SAJS.1993

8. Kruger D, Veller MG. Exposure to key surgical procedures during general surgical training in South Africa. S Afr J Surg. 2014;52(4):96-100. Available from: http://dx.doi.org/10.7196/ sajs. 2162 
9. Connor K, Teasdale E, Johnson S, et al. Surgical training in South Africa - A practical guide to getting a job. Int J Surg. 2014;12(3):S75. Available from: http://dx.doi.org/10.1016/j. ijsu.2014.08.17

10. Degiannis E, Oettle GJ, Smith MD. Surgical education in South Africa. World J Surg. 2009;33:170-3. Available from: http:// dx.doi.org/10.1007/s00268-008-9815-2

11. Smith MD. Perspectives of South African General Surgeons regarding their postgraduate training. SAJS. 2014;52(3):66.

12. Van Rensburg HCJ. South Africa's protracted struggle for equal distribution and equitable access - still not there. Hum Resour Health. 2014;12(26):1-16. Available from: http://dx.doi. org/10.1186/1478-4491-12-26

13. Thomson SR, Baker LW. Health care provision and surgical education in South Africa. World J Surg. 1994;18(5):701-5.

14. Ibrahim A, Ibrahim ZD, Edaigbini SA, et al. Teaching the surgical craft: Surgery residents perceptions of the operating theatre education environment in a tertiary institution in
Nigeria. Niger J Surg. 2013;19(2):61-7. Available from: http:// dx.doi.org/10.4103/1117-6806.119240

15. Greensmith M, Cho J, Hargest R. Changes in surgical training opportunities in Britain and South Africa. Int J Surg. 2015;25:76-81. Available from: http://dx.doi.org/10.1016/j. ijsu.2015.11.052

16. Terpstra OT, Stegeman JH. Effects of the restriction of working time for residents: A Dutch perspective. J Grad Med Educ. 2011;3(4):462-4. Available from: http://dx.dori.org/10.4300/ JGME-D-11-00202.1

17. Apostolou C, Panieri E. National survey of surgeon's attitudes to laparoscopic surgical training in South Africa. SAJS. 2007;47(3):86-91.

18. Kotsis SV, Chung KC. Application of see one, do one, teach one concept in surgical training. Plast Reconstr Surg. 2013;131(5):1194-1201. Available from: http://dx.doi. org/10.1097/PRS.0b013e318287a0b3 